\title{
Effect of Acclimatization Time to Microbial Cell Growth and Biosynthesis of Mesophilic Gammaproteobacterium, in Orbital Shake Flasks
}

\author{
Abd. Aziz Mohd Azoddein ${ }^{1}$, Mani Malam Ahmad ${ }^{1, a}$, Rosli Mohd Yunus ${ }^{1}$ and Nik Meriam Nik Sulaiman ${ }^{2}$ \\ ${ }^{1}$ Faculty of Chemical and Natural Resources Engineering, University Malaysia Pahang, Lebuhraya Tun Razak, \\ 26300 Gambang, Kuantan, Pahang, Malaysia \\ ${ }^{2}$ Department of Chemical Engineering, Faculty of Engineering, University Malaya, Kuala Lumpur, Malaysia
}

\begin{abstract}
Growth pattern of Pseudomonas putida (ATCC 49128), was found to predominantly rely on the age of the inoculums, prior to its contact with physical and chemical agents and nutrient availability. Under suitable inoculums, bacteria tend to grow faster in a batch type of growth pattern which is usually sustained until after nutrient depletion. In this research, the bacterial growth pattern was studied in an incubator shake flask using $8 \mathrm{~g}$ nutrient media and physical operational parameters temperature of $37{ }^{\circ} \mathrm{C}$ and agitation of $180 \mathrm{rpm}$ over a period of 24, 48 and 72 hours. Prior to this, P. putida was added into $20.0 \mathrm{ml}$ nutrient broth and incubated in an incubator for 24 hours at $37{ }^{\circ} \mathrm{C}$, before adding it to $180 \mathrm{ml}$ nutrient broth $30 \%$ $\left(\mathrm{v} / \mathrm{v}^{1-}\right)$. Growth, via acclimatization was initially observed after $1 \mathrm{hr}$ of inoculation with an overwhelming exponential growth of 2.69-2.57 within first $24 \mathrm{hr}$, exceeding the 48 and $72 \mathrm{hrs}$ ranges. This additionally relates to particular cell biomass growth rate $(\mu)$ of $0.58 \mathrm{hr}^{1-}, 3.87$ number of generation $(\mathrm{n})$, generation time $(g) 1.09$ and growth rate constant $(k)$ of $0.01 \mathrm{hr}^{1-}$, achievable within $24 \mathrm{hrs}$. It was therefore concluded that the sensitivity of this strain to time is significant, as optimal growth was achieved within $24 \mathrm{hrs}$ of acclimatization, thereby showing a drastic reduction in the time of growth.
\end{abstract}

\section{Introduction}

Metabolism refers to the concept of biochemical activities that enable the organisms grow and reproduce effectively in an appropriate substrate. This includes its utilization for cell repair and biosynthesis as well as well other necessary physiological transformations associated with this [1]. These biochemical activities involve the brake down of substrate through dissimilation to release energy, as well as assimilation of organic and inorganic substrates for growth and biosynthesis of bacterial cells. Growth in microbes is the most essential response to their physiochemical environment [2].

Upon inoculation into a suitable media, this gram negative, aerobic and gammaproteo bacterium selectively takes up nutrients from the medium for biosynthesis [3]. The initial lag growth phase is a period of cell change in accordance with the new environment. The increase in cell is very minimal and is dependent upon cells' former history (age, pre-exposure to damaging and toxic substances and

\footnotetext{
${ }^{\mathrm{a}}$ Corresponding author: mmahmadu@gmail.com
} 
the medium). In commercial production of enzyme, the initial growth stage used to be a brief as possible, depending on the type of inoculum used [4].This is then followed by exponential or log, within which the isolate have modified to the new medium. Thereafter these cells now divide aggressively which usually occurs at 15-20 minutes rate, with a balanced cell biomass production phase [5]. This is the peak nutrient utilization stage and growth rate is directly proportional to nutrient concentration in the medium During the last stage refer to as stationary or death phase, growth rate is equal to the death phase, thus termed as zero growth rates and is characterized by nutrient exhaustion and metabolites accumulation [6]. Despite this zero growth, yet the cells retained active metabolic activities. Ideally, growth in bacterial cells follows a geometric progression pattern (i.e. $2^{0} ! 2^{1} ! 2^{2} ! 2^{\mathrm{n}}$ ) which is depicted using Monod growth model [7].

$$
X_{t}=X_{\mathrm{oe}}{ }^{\mathrm{ut}}
$$

where $\mu$ is microbial biomass increase or specific growth rate $\left(\mathrm{h}^{\mathrm{r}-1}\right), \mathrm{X}_{\mathrm{t}}$, cell growth over a period of time $\mathrm{t}$, and $\mathrm{X}_{0}$ initial cells number. Taking log of the two sides, the above model equation is given as

$$
\log X_{t}=\log X_{0}+\mu t
$$

Specific growth rate, $\mu$ which is addition of cell biomass per unit time, is given;

$$
\mu=\frac{\ln x_{t}-\ln x_{0}}{t}
$$

Number of generation, $\mathrm{n}$

$$
n=3.3 \ln \frac{X_{t}}{X_{0}}=3.3 \ln \frac{O D}{O D_{0}}
$$

Generation time, $\mathrm{g}$ time required for cells to doubled

$$
g=\frac{t}{n}
$$

where $\mathrm{t}$ is the period of active cell growth given in days, hours or minutes, $n$ number of generation The number of generation at an active cell growth phase is termed as growth rate constant $k$.

$$
k=\ln \frac{2}{g}
$$

This piece of work is envisage at evaluating the growth pattern of $P$. putida over a specified period upon subjecting it to single nutrient medium and physical operational parameters of an orbital shake flasks. Acclimatization time is an important aspect to microbiologist, especially as it applies to industrial and biotechnological application in fermentation, bioremediation, enzyme production among others. Therefore, the finding will be of significant value when utilizing this isolates in any experimental and real application.

\section{Methodologies}

\subsection{Strain and Cultivation}

The $P$. putida (ATCC 49128) with its growth media was obtained from a licensed supplier in USA through a local agent Merck (Malaysia) Sdn. Bhd. Culture media was formulated by required amount of nutrient in a liter of water and agitated vigorously with magnetic stirrer on a hot plate until it 
dissolved. The solution was then autoclave at $121^{\circ} \mathrm{C}$ for 15 minutes; and to cool to a temperature of less than $40^{\circ} \mathrm{C}$ inside a safety cabinet before transferring to individual $20 \mathrm{ml}$ sampling bottles. Seeding was done by suspending 1-3 loops of the inoculum for effective viability, into the previously prepared media in $20 \mathrm{ml}$ bottles $10 \%\left(\mathrm{wv}^{1-}\right)$. The culture was then incubated at $37^{\circ} \mathrm{C}$ for one day inside a microbiological incubator. Thereafter, the isolate was emptied into a $150 \mathrm{ml}$ nutrient broth $30 \%\left(\mathrm{vv}^{1-}\right)$ [8], and placed into the orbital shaker. These processes were done aseptically inside a biosafety cabinet, as well in according to standard. It was indicated that multiple loops seeding ensure proper bacterial growth [3]. The orbital shaker was operated at $37^{\circ} \mathrm{C}$ and $180 \mathrm{rpm}$. The experiment was conducted in three different acclimatization times of 24,48 and 72 hours, respectively.

\subsection{Analysis of sample for different $P$. putida growth parameters}

For growth determination, $2.5 \mathrm{ml}$ Aliquots samples were withdrawn periodically using $5 \mathrm{ml}$ syringe aseptically. Growth was measured using U-VIS Spectrophotometer (Hatachi, U-1800), at OD $_{600} \mathrm{~nm}$ wavelength. This mechanism was based on the principle of light diffraction, reflection and absorption by suspended cells. This technique provides fast, easy, inexpensive and reliable for estimating cell density. The magnitude of transmitted light is proportional to cell density or biomass regulated by media absorption and scattering. While for cell dry weight measurement, $1 \mathrm{ml}$ aliquot sample was collected in a centrifuge vails and spin at $12,000 \mathrm{rpm}$ for $15 \mathrm{~min}$. The floating liquid was disposed and the sediment washed in a $5 \%$ saline solution and centrifuged again, then oven dried at $100^{\circ} \mathrm{C}-110^{\circ} \mathrm{C}$ for $1 \mathrm{hr}$. The mass was measured and dried repeatedly until a stable weight was obtained [9].

\section{Results and Discussion}

\subsection{Effect of Acclimatization time of $P$. putida Growth}

Result from Figure 1, Table 1, shows that the cultured P. putida has been acclimatized within 24 hours and adapted well to its new environment of shake flask. Meanwhile, it took this strain just an hour to adapt and start growing (lag phase) after inoculation. The cell optical density (OD), number of generation, $n$ and growth rate constant, $k$ decreased to zero in the lag phase. In this condition, $P$. putida is considered to be in non-productive period and more time needed to adapt to the new environments. During this period, molecular components were usually re-constituted largely due to slight increase in cell concentration. Thereafter, growth rate increases in the subsequent 2 to 5 hours and as a result the cell density also increased. Consequently, the OD and the exponential cell growth were at their maximum values of 2.57 and 2.70 within 24 hours acclimatization time, respectively. This period correspond to the rapid production of new cell measured as biomass. However, growth was maintained and observed to decelerate gradually thereafter. This corresponds to a slight upward shift of the medium $\mathrm{pH}$ (Tab. 1), thus drastic increase in metabolic rates of the isolate. Increase in cell biomass $(\mu)$ of $0.58 \mathrm{hr}^{-1}$ in $24,0.56 \mathrm{hr}^{-1}$ in 48 and $0.55 \mathrm{hr}^{-1}$ in 72 hours acclimatization time, respectively. Specific growth rate, $(\mu)$ or cell biomass increase is used to indicate the average growth proportion of the entire cells in a culture medium [10].

Based on the analysis, the maximum number of generation, $\mathrm{n}$ were 3.87 for 24 hours acclimatization, 3.57 for 48 hours acclimatization and 3.61 for 72 hours acclimatization. While the calculated maximum generation time, g were 14.00 hours for 24 hours, 2.00 hours for both 48 hours and 72 hours acclimatization. Also, the growth rate constant, k estimated were $0.01 \mathrm{hr}-1,60 \mathrm{hr}-1$ and $0.66 \mathrm{hr}-1$ for 24,48 , and 72 hours, respectively. Based on aforementioned growth parameters recorded, it was quite glaring that, this isolate require a minimum of 24 hours to acclimatize and start to grow effectively in its new environment. 
Table 1. Summary of parameters related to P. putida growth for 24 h, 48 and 72 hours acclimatization time

\begin{tabular}{lllllll}
\hline $\begin{array}{l}\text { Growth Parameter Time } \\
\text { (hr) }\end{array}$ & \multicolumn{4}{c}{ Min } & \multicolumn{3}{c}{ Max } \\
\cline { 2 - 7 } & $\mathbf{2 4}$ & $\mathbf{4 8}$ & $\mathbf{7 2}$ & $\mathbf{2 4}$ & $\mathbf{4 8}$ & $\mathbf{7 2}$ \\
\hline Proportionate cell growth & & & & & & \\
$(\mu)$ & 0.58 & 0.56 & 0.55 & - & - & - \\
OD $(600 \mathrm{~nm})$ & 0.17 & 0.17 & 0.17 & 2.57 & 2.09 & 2.14 \\
Exponential cell growth (ln & & & & & & \\
OD $\left./ \mathrm{OD}_{\mathrm{o}}\right)$ & 0.05 & 1.79 & 2 & 2.7 & 2.49 & 2.52 \\
Number of Generation $n$ & 0.07 & 2.57 & 2.86 & 3.87 & 3.57 & 3.61 \\
Generation Time $g(\mathrm{hr})$ & 1.09 & 1.17 & 1.05 & 1.76 & 1.68 & 1.66 \\
Growth rate Constant, $k$ & 0.05 & 0.42 & 0.42 & 0.63 & 0.6 & 0.11 \\
pH & 6.24 & 6.59 & 6.6 & 7.46 & 7.42 & 7.47 \\
\hline
\end{tabular}

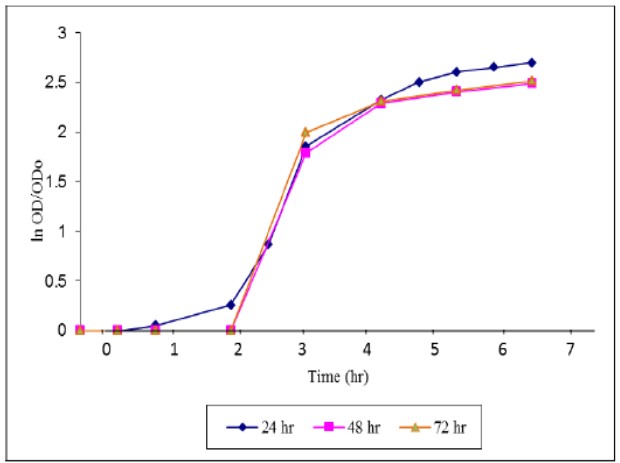

Figure 1. Exponential cell growth of $P$. putida within first 6 hours of inoculation

\subsection{Determination of $\boldsymbol{P}$. putida Growth Parameters}

The results showed a drastic increased in P. putida growth within the first six hours of inoculation with corresponding OD range of 0.21 to 1.98 . This can be seen as per average number of generation 3.19 and the maximum growth rate constant value of $0.37 \mathrm{hr}^{1-}$. It was reported that based on the growth parameters, different microorganisms used to grow and acclimatized under the distinct microbial media [6]. This is significant for optimizing nutrient composition as well as determining its effects on the bacteria culture (Table 2). Based on the findings from this study, it can be seen that $P$. putida growth pattern could fully be understood from experimentation in an enclosed system of orbital shake flask, which is considered a batch culture.

Table 2: Different growth parameters related to P. putida growth over 30 hours period

\begin{tabular}{rccccc}
\hline $\begin{array}{c}\text { Time } \\
\text { (hr) }\end{array}$ & OD & $\begin{array}{c}\text { Exponential cell } \\
\text { growth }(\mathbf{l n} \\
\text { OD/OD }\end{array}$ & $\begin{array}{c}\text { Number of } \\
\text { generation } \\
(\boldsymbol{n})\end{array}$ & $\begin{array}{c}\text { Generation } \\
\text { time }(\boldsymbol{g})\end{array}$ & $\begin{array}{c}\text { Growth } \\
\text { Rate } \\
\text { Constant } \\
(\boldsymbol{k})\end{array}$ \\
\hline 2.00 & 0.21 & 5.36 & 0.00 & - & 0.29 \\
4.00 & 0.68 & 6.53 & 1.67 & 2.40 & 0.37 \\
6.00 & 1.98 & 7.59 & 3.19 & 1.88 & 0.32 \\
7.00 & 2.10 & 7.65 & 3.28 & 2.14 & 0.29 \\
8.00 & 2.25 & 772 & 3.38 & 2.37 & 0.24 \\
10.00 & 2.36 & 7.77 & 3.44 & 2.90 & 0.22 \\
11.00 & 2.39 & 7.78 & 3.46 & 3.18 & 0.09 \\
26.00 & 2.59 & 7.86 & 3.58 & 7.83 & 0.09 \\
28.00 & 2.59 & 7.86 & 3.58 & 7.83 & 0.08 \\
30.00 & 2.57 & 7.85 & 3.57 & 8.41 & \\
\hline
\end{tabular}


During the first 6 hours of the 30 hour experiment the isolate attained a maximum growth of 7.86 . After 6 hours, it was noted that the pattern of cell concentration is consistent and decreased slightly with time and an equilibrium growth rate was recorded. The proportional cell biomass increase $(\mu)$ was found to be $0.96 \mathrm{hr}^{-1}$. It was reported that growth is limited mainly by factors such as temperature, substrates concentration and composition as well as genomic of the organism itself [5]. Number of generation, $n$ for $P$. putida was 1.67 to 3.58 , while the generation time, $g$, which is the time interval between two cell divisions, is from 1.88 to 8.41 hours. The growth rate constant, $k$ is in the range of 0.08 to $0.37 \mathrm{hr}^{-1}$, which was a measure of how fast the cells are dividing in a culture for the first 2 to 6 hours from the 30 hours experiments. The result obtained agreed with the previous findings where $P$. putida was found to overwhelmingly grow in a recalcitrant medium containing toxic organic wastes [11].

\subsection{Determination of Biomass Synthesis Using Cell Dried Weight}

Figure 2, presented the finding for P. putida (ATCC 49128) cell dried weight $\left(\mathrm{gl}^{1-}\right.$ ). To better understand the nature of this growth pattern, a calibration curve of OD was plotted against cell dryweight, although the curve tend to be non-linear as OD approaches 0.30 [6]. The result shows that cell dried weight increase was directly proportional to optical density. Increase in OD is based on the principle of rate of light absorbance passing through a medium containing cell biomass. Consequently as the cell growth increase due to biosynthesis of cell biomass the less the amount of light passing through and the higher the rate of light absorbed on to the cell surface.

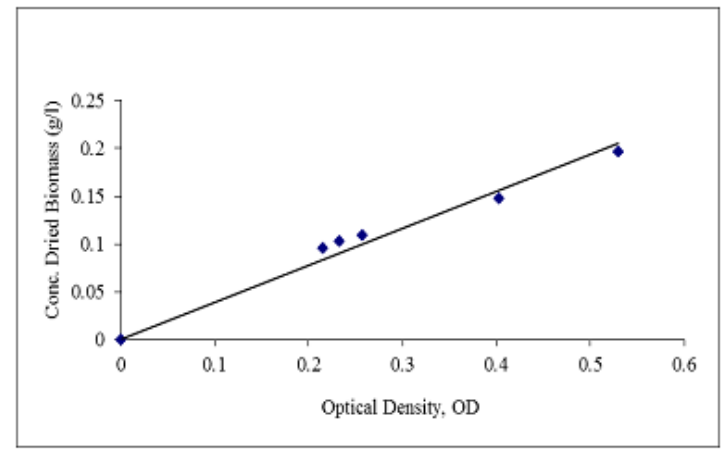

Figure 2. Pseudomonas putida cell dry weight curve

\section{Conclusions}

In conclusion, it was obvious that P. putida (ATCC 49128) bacterial isolate could be cultivated in a simple media composition under physical operational parameters of orbital shake flasks within a shortest period of less than 24 hours. Acclimatization indeed was found to be affected by many factors such as age of the culture and stress phenomenon or growth limiting factors. Growth was exponentially recorded within the first six hours of inoculation with lag phase lasting not more than an hour. Based on the condition applied in the medium, the P. putida growth usually kick-start only after a short period of time of inoculation into fresh medium. This period may be shorten or extended, but rely on the nutrient composition, genetic composition and age of the culture as well. However, generation time was found to be extended if the culture is taken from an old culture and transferred into fresh medium, even though the cells in the culture are viable. Results from this study indicated that P. putida, requires a minimum of $24 \mathrm{hr}$ to adapt and grow optimally when inoculated into a fresh medium, though significant values were also observed for 48 and 72 hours, respectively. This further substantiated the significant role of acclimatization time on growth and biosynthesis of this isolate. 


\section{Acknowledgement}

We wish to sincerely register our appreciation to University Malaysia Pahang, for their financial support through local research grant.

\section{References}

1. Zinkernagel, K.F.H.K.A.B.J.E. and R.M., 2005. Medical Microbiology 5th Edition, ed., Stutgart: Thieme. Available at: http://pgim.srilanka.healthrepository.org/handle/123456789/9873.

2. Volesky, B. (2007). Biosorption and me. Water Research, 41(18), 4017-4029. http://doi.org/10.1016/j.watres.2007.05.062

3. Fonseca, P., Moreno, R., \& Rojo, F. (2011). Growth of Pseudomonas putida at low temperature: Global transcriptomic and proteomic analyses. Environmental Microbiology Reports, 3(3), 329339. http://doi.org/10.1111/j.1758-2229.2010.00229.x

4. Rashedi, H., Izadi, A., Bidhendi, M. E., \& Rashedi, H. (2015). Optimization of Operational Parameters in Rhamnolipid Production by Pseudomonas aeruginosa MM1011 in a Miniaturized Shaken Bioreactor, 2(3), 271-278.

5. Shea, M., Litvin, S., \& Chirnside, A. (2013). The Effect of Nitrogen, Sulfur , and Phosphorus Compounds on Bioremediation of Oil Spills by Pseudomonas fluorescens and Bacillus subtilis, 30-37

6. Shuler, M.L. and Kargi, F. 2002. Bioprocess Engineering. Sec. Ed. Prentice Hall PTR, Prentice-H all, Inc. Upper Saddle River, NJ

7. Bitton, G. (2001). Wasterwater microbiology (Vol. 40). http://doi.org/10.1002/15213773(20010316)40:6<9823::AID-ANIE9823>3.3.CO;2-C

8. Standbury, P.F., Whitaker, A. and Hall, S. J. (1984). P. of F. T. O. B. H. (1984). Principle of Fermentation. Standbury, P.F., Whitaker, A. and Hall, S. J. (1984). Principles of Fermentation Technology. Oxford: Butterworth Heinemann (2nd ed., Vol. 53). OXFORD: BUTTERWORTH HEINEMANN. http://doi.org/10.1017/CBO9781107415324.004

9. Bratbak, G., \& Dundas, I. (1984). Bacterial dry matter content and biomass estimates. Applied and Environmental Microbiology, 48(4), 755-757.

10. Lee, K., Park, J. W., \& Ahn, I. S. (2003). Effect of additional carbon source on naphthalene biodegradation by Pseudomonas putida G7. Journal of Hazardous Materials, 105(1-3), 157-167. http://doi.org/10.1016/j.jhazmat.2003.08.005

11. Abuhamed, T., Bayraktar, E., Mehmetoğlu, T., \& Mehmetoğlu, Ü.”. (2004). Kinetics model for growth of Pseudomonas putida F1 during benzene, toluene and phenol biodegradation. Process Biochemistry, 39(8), 983-988. http://doi.org/10.1016/S0032-9592(03)00210-3 